\title{
La riqueza forestal de Rusia
}

$\mathrm{L}$ os acontecimientos de finales de la década de los ochenta y principios de los noventa en la Unión Soviética continúan siendo objeto de atención, tanto en el interior de la Federación Rusa como en el resto del mundo. El estado totalitario con el monopolio del poder y la completa dominación estatal de la propiedad, que prevaleció durante más de cuarenta años, habían llegado a su fin. ${ }^{1}$ El proceso de perestroika estableció reformas en lo social, lo político y lo económico que arrastraron al país a una dolorosa transición hacia la economía de mercado. ${ }^{2}$ En el contexto mundial este proceso, que conllevó a la desintegración de la Unión Soviética y el fin de una de las grandes superpotencias, transformó el sistema internacional y puso fin a la guerra fría, donde el bipolarismo militar y el enfrentamiento ideológico del comunismo y el capitalismo fueron las principales características durante la segunda mitad del siglo $\mathrm{XX} .^{3}$

El país ruso continúa en su proceso de transformación luchando por alcanzar, mediante su estructura productiva y su riqueza nacional, los estándares exigidos por esta nueva era global. Los bienes naturales de Rusia son muchos. En este artículo me enfocaré en una de las máximas fortalezas del territorio, que al mismo tiempo resulta ser un bien público mundial: los recursos forestales.

La importancia de destacar este bien natural se debe a tres motivos: 1) Rusia es el país que tiene mayor superficie forestal en el mundo, 851 millones de hectáreas. Es decir, poco más de la mitad de la superficie territorial rusa está cubierta por bosque; lo que representa el 22 por ciento de la cubierta forestal del planeta. 2) El surgimiento de los temas ambientales en la agenda internacional. ${ }^{4} 3$ ) La paulatina

* Investigadora del Departamento de Estudios del Pacífico, de la Universidad de Guadalajara.

ORCID http://orcid.org/0000-0002-4553-8141 apertura comercial de la economía rusa, donde el incremento de la productividad y de los intercambios de productos forestales se han vuelto evidentes.

\section{La posición forestal rusa y el valor de los recursos forestales}

La extensión territorial mundial consta de 131’396,180 km², de los cuales, sólo el 30 por ciento de la superficie está cubierta por bosque. Los bosques tropicales y subtropicales comprenden el 56 por ciento de los bosques del mundo (selvas), y los bosques templados y boreales el 44 por ciento. ${ }^{5}$

Entre Rusia, Brasil, Canadá, Estados Unidos e Indonesia ${ }^{6}$ se encuentra repartida poco más de la mitad de la superficie forestal del planeta. Al mismo tiempo, ellos tienen la responsabilidad de hacer el mejor uso de estos recursos naturales, debido a que invariablemente fungen como pulmones del mundo.

El valor real de los recursos forestales -bosques o selvas- proviene de sus características; es decir, no solamente representan un bien económico al ofertarse comercialmente como un producto final o de transformación (bajo las leyes de la oferta y la demanda), sino que estos recursos generan costos y beneficios que no van a parar a sus propietarios o a los consumidores, debido a que dentro de las funciones de los recursos forestales están las de generar oxígeno, regular el balance del agua y la temperatura de la tierra (al facilitar la infiltración de los mantos freáticos), además de permitir la proliferación de una gran diversidad biológica, y ser fuente de recreación, entre otras. ${ }^{7}$

Dichos beneficios, que se pierden cuando se comercia con los bosques y las selvas y de los que nadie se hace responsable, son 
externalidades negativas que provocan fallos de mercado. El acceso a la compra y venta de la madera o el cambio de la superficie forestal para otros fines - como la agricultura o la urbanización-no están limitados de acuerdo con su valor de escasez: en este sentido no hay compensación (a través de los precios) a la sociedad por el agotamiento de un bien. ${ }^{8}$

Los economistas afirman que estas externalidades establecen a los recursos forestales como un bien esencial al no existir en el mundo ningún otro elemento que los sustituya, por ejemplo, el dióxido de carbono por aire puro, ni otro espacio en donde se desarrolle la vida de una gran diversidad biológica, ${ }^{9}$ o el desarrollo del ciclo del agua en nuestro planeta. ${ }^{10}$ Son estas mismas peculiaridades las que convierten a estos recursos en bienes públicos mundiales, es decir, los bosques y las selvas emiten externalidades (negativas o positivas) que se difunden indivisiblemente por toda la tierra. ${ }^{11}$

En suma, el valor comercial y esencial de los recursos forestales, más la concentración del 22 por ciento de ellos en el territorio ruso, despiertan el interés de la comunidad internacional al sentirse beneficiados o perjudicados por el buen o mal uso de éstos.

Resulta interesante hacer un análisis comparativo entre Rusia y los cuatro países con mayor superficie forestal de la tierra. Esto se hará sobre tres variables específicas: la deforestación, las exportaciones y las importaciones. Los resultados nos permitirán hacer una evaluación general sobre la manera en que están siendo utilizados la mayor parte de los recursos forestales de mundo, ya que a pesar de ser un bien esencial, la disminución de este bien natural es una realidad día a día. ${ }^{12}$

\section{La Cumbre de Rio y los principales poseedores de los recursos forestales en el planeta}

Aunque desde los años sesenta los temas ambientales empezaron a debatirse en los países desarrollados de occidente, estos asuntos no formaron parte de la agenda internacional de las economías del mundo hasta principios de los noventa. ${ }^{13}$ La última década del siglo XX estuvo marcada por el surgimiento del papel prioritario de los asuntos ambientales. En 1992 la Conferencia de las Naciones Unidas sobre Medio Ambiente y Desarrollo (celebrada en Rio de Janeiro, Brasil) exhortó a los países miembros a "hacer compatible la protección ambiental con el crecimiento y desarrollo económico". ${ }^{14}$ A partir de entonces al interior de los países se reestructuró a través de normas y leyes un manejo forestal más acordes con las exigencias del desarrollo sustentable requerido en esta nueva época. ${ }^{15}$

En este sentido, se esperaría que con el transcurso de los años mejorara el manejo de los recursos forestales. Pero como lo muestran

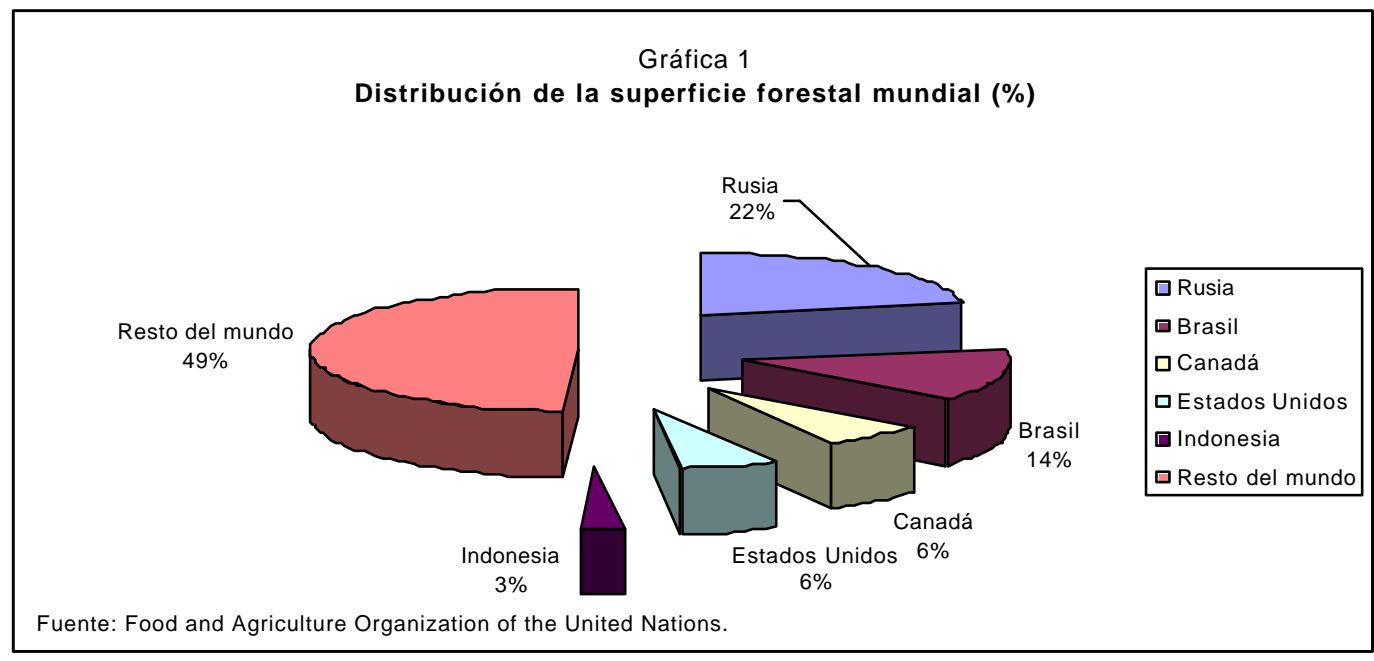


las cifras de Food and Agriculture Organization of the United Nations (FAO), los cambios realizados en el marco legal forestal aún no han dado los resultados deseados, debido a que la superficie forestal mundial, de 1990 a 2000 , tuvo una disminución de poco más de 90 millones de hectáreas, lo que representa una reducción del 0.24 por ciento - promedio anual- del área arbolada del mundo.

$\mathrm{Al}$ hacer un análisis de diez años consecutivos (1990-2000) resulta interesante y esperanzador saber que al menos tres de los grandes poseedores de bosques y selvas emplean prácticas de sustentabilidad, y que si bien no incrementaron su superficie forestal tampoco la disminuyeron: es el caso de Estados Unidos, Rusia y Canadá. Los dos primeros aumentaron su extensión forestal a través de plantaciones ${ }^{16}$ y la regeneración natural, en una proporción aproximada de 388 y 135 mil hectáreas, respectivamente. Canadá la mantuvo sin cambios. Por lo tanto, esto tres país difieren de la tendencia mundial, la cual es negativa.

En Brasil e Indonesia sucede lo contrario: durante el mismo lapso disminuyeron $\mathrm{su}$ superficie forestal un promedio anual de 2,309 y 1,312 mil hectáreas, respectivamente; es decir, juntas estas dos economías contribuyeron con casi el 40 por ciento del total de la deforestación mundial en la década de los noventa. Si sumamos a los dos países con disminución forestal y a las tres naciones que mantuvieron e incrementaron su área boscosa, estos últimos sólo representan el 15 por ciento de los dos primeros. En suma, en este conjunto de países la cantidad de hectáreas deforestadas fue 85 por ciento mayor que la superficie reforestada. Si se compara la tendencia mundial sobre disminución de la superficie arbolada con la de Brasil e Indonesia, evidentemente las de estos dos países son superiores a la primera, debido a que disminuyeron su cubierta forestal en un promedio anual de 1.17 y 0.41 por ciento respectivamente, mientras que la propensión de la disminución de la cubierta forestal mundial fue de 0.24 por ciento, promedio anual durante 1990-2000.

Rusia, el país con la mayor cubierta forestal del planeta, hace en términos relativos un buen manejo de los recursos forestales al establecer métodos y prácticas de plantación que sustituyen correctamente la tala de árboles, empleada con fines comerciales o de combustible. Pero en algunas áreas del territorio ruso no se aplican las prácticas forestales generales del país, lo que conlleva a ser catalogadas por los organismos no gubernamentales

Cuadro 1

Cubierta forestal y deforestación

\begin{tabular}{lccccc}
\hline \multicolumn{1}{c}{ Países } & $\begin{array}{c}\text { Superficie (miles } \\
\text { de hect.) }\end{array}$ & $\begin{array}{c}\text { Superficie } \\
\text { forestal (miles } \\
\text { de hect.) }\end{array}$ & $\begin{array}{c}\text { Porcentaje } \\
\text { forestal del total }\end{array}$ & $\begin{array}{c}\text { Promedio anual } \\
\text { de deforestación } \\
\text { (miles de hect.) } \\
1990-2000\end{array}$ & $\begin{array}{c}\text { Porcentaje } \\
\text { anual de } \\
\text { deforestación } \\
\text { (1990-2000) }\end{array}$ \\
\hline Brasil & 845,651 & 543,905 & 64.3 & 2,309 & 0.41 \\
Canadá & 922,097 & 244,571 & 26.5 & 0 & 0.00 \\
Estados Unidos & 915,896 & 225,993 & 24.7 & -388 & -0.17 \\
Indonesia & 181,157 & 104,986 & 58.0 & 1,312 & 1.17 \\
Rusia & $1,688,850$ & 851,392 & 50.4 & -135 & -0.02 \\
Mundo & $13,139,618$ & $3,869,453$ & 29.4 & 9,319 & 0.24 \\
\hline
\end{tabular}

Fuente: Food and Agriculture Organization of the United Nations. 
como zona de desastre ecológico. Es el caso de la isla de Sajalin, en el extremo oriente ruso. Vadislav Vaklov, activista de Vigilancia Ambiental de Sajalin, señaló que "casi todas las actividades forestales de esta isla violan las leyes regionales o federales". ${ }^{17}$ Sin embargo, al hacer un recuento de los daños entre las dos caras de la moneda (deforestación y reforestación) en Rusia, según los datos aquí expuestos, el buen manejo de las prácticas forestales es lo que prevalece. Esto no sucede con las cifras del planeta, ya que como lo muestra el cuadro 1, a escala mundial en la década de los noventa la reforestación perdió la batalla contra la deforestación. Lo que al final concluye con la degradación paulatina del planeta.

\section{Comercio internacional de los productos forestales}

Otra característica de la década de los noventa es el polémico debate entre el comercio y el medio ambiente generado, entre muchos motivos, por las externalidades inherentes a éstos. Un ejemplo citado por la Comisión Económica para América Latina (CEPAL) ilustrará mejor lo anterior: "un país con grandes áreas de bosque poseería ventajas comparativas en la producción y exportación de productos forestales. Sin embargo, también tendría ventaja comparativa en la exportación de servicios de absorción de dióxido de carbono o en biodiversidad. Pero como estos servicios no son considerados por el sistema de precios de mercado, éste tampoco traducirá ese beneficio social que generan los bosques al resto del mundo en beneficio privado, subestimando de esa manera el verdadero valor de este recurso natural". ${ }^{18}$

El panorama es complejo; y da como resultado la no conclusión de acuerdos entre los defensores del comercio y los protectores del medio ambiente, ya que estos últimos acusan a los primeros de que, en su afán de liberalizar el comercio, utilizan prácticas y políticas con implicaciones adversas al medio ambiente. ${ }^{19}$ Los especialistas en el libre comercio "temen que surjan nuevas formas de proteccionismos comerciales -barreras a los productores extranjeros para acceder al mercado reduciendo las ganancias en eficiencia de un comercio más libre- bajo el disfraz político de la mejora ambiental". ${ }^{20}$ Para otros, el crecimiento del comercio contribuye al aumento de la riqueza y la difusión tecnológica, lo que genera la posibilidad de que la sociedad proteja sus recursos naturales. Sostienen que "el comercio irrestricto puede ser dañino a su medio ambiente, especialmente en los países con políticas ambientales débiles o inexistentes". ${ }^{21}$

El daño ambiental se encuentra determinado más por la ausencia o debilidad de las políticas ambientales internas que por efecto mismo del comercio. Es reconfortante saber que países como Rusia, Estados Unidos y Canadá ya utilizan prácticas de desarrollo sustentable - en el manejo de los bosques-como política estable.

Aunque en proporción al comercio total mundial de bienes y servicios los productos forestales sólo representan alrededor del 3 por ciento, las cifras alcanzadas durante los noventa mostraron una tendencia positiva, con amplias posibilidades de incrementarse. Cabe destacar que dentro de ese conjunto de países tenemos dos de los principales comercializadores del mundo: Estados Unidos y Canadá.

La diferencia de productos es una de la causas por las que estos grandes poseedores de cubierta forestal importan y exportan al exterior, relativamente, grandes cantidades de este bien. Es evidente que el mayor importador del grupo es Estados Unidos y el menor, Brasil. Las importaciones de Rusia sólo representan 4 por ciento de las compras al exterior de Estados Unidos.

Como se aprecia en el cuadro 2, en el transcurso de ocho años, las importaciones de estos países tienden a incrementarse, especialmente para Rusia, quien presentó un crecimiento promedio anual de 26.2 por ciento, mientras que Estados Unidos tuvo el menor incremento $(8.4 \%)$. Un dato que vale la pena 

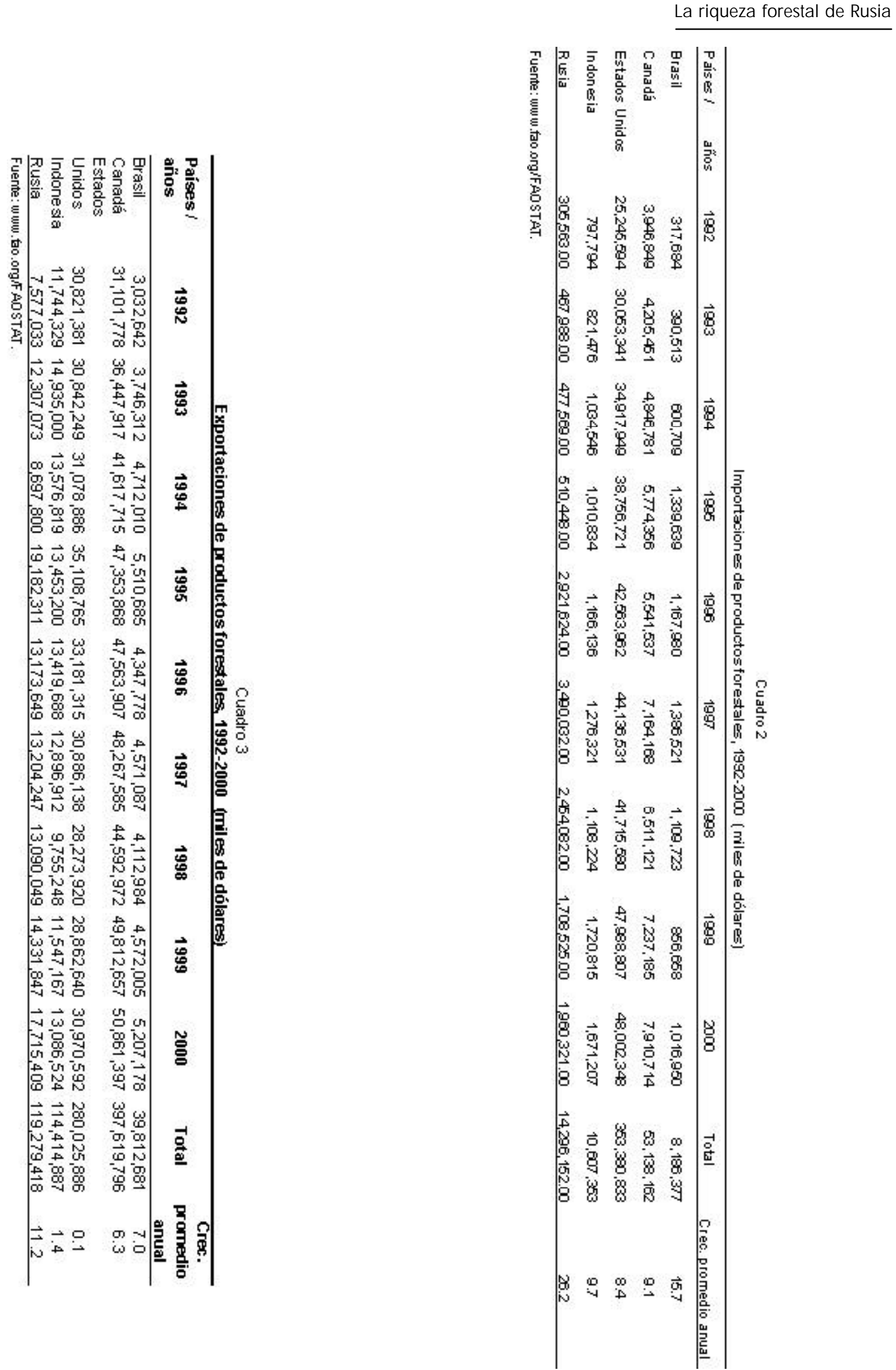
resaltar es que todos estos países mostraron una disminución de sus importaciones en 1998, debido al impacto de la crisis económica de los países asiáticos.

En cuanto a exportaciones se refiere, Canadá es el principal proveedor de productos madereros del grupo y Brasil, el menor. Rusia es quien presenta mayor crecimiento promedio anual de ventas al exterior. Las exportaciones de Estados Unidos, durante el período analizado, prácticamente se han estancado ( 0.1 por ciento de crecimiento promedio anual). Las exportaciones de Brasil — país que presentó mayor deforestación de sus selvas y la segunda nación con mayor superficie forestal- son relativamente bajas si las comparamos con el resto del conjunto; la no congruencia de datos nos puede dar indicios de la presencia de tala clandestina o de utilización de la superficie forestal para otros fines (agricultura o urbanización ${ }^{22}$ ) y del retraso tecnológico de la industria forestal brasileña.

En el período 1992-2000, el comercio total -importaciones más exportaciones- de productos madereros de los cinco países analizados alcanzó la cifra de 1390761 millones de dólares, de los cuales entre Estados Unidos y Canadá acapararon casi el 80 por ciento, mientras que Rusia sólo contribuyó con el 9.6 por ciento, quedando la participación de Brasil con sólo el 3 por ciento.

A excepción de Estados Unidos, los demás países presentan saldo positivo en su balanza comercial forestal. Dentro de las economías superavitarias las importaciones de Indonesia, en proporción a las exportaciones, son menores ya que las cantidades importadas solo representan 9 por ciento de las cifras exportadas, mientras que las de Brasil son las mayores (21\%). Para Rusia y Canadá las compras del exterior representan 12 y 13 por ciento, respectivamente, de las ventas al mundo de productos forestales. En cambio, para Estados Unidos las importaciones representan 126 por ciento del total de exportaciones del período analizado.

Cabe destacar que en Rusia las exportaciones de todo tipo de troncos de madera — con poco valor agregado- son en proporción mayores que las que requieren de algún tipo de proceso industrial. En el caso de las importaciones la situación se invierte: los productos procesados (como la pulpa maderera o el papel) son los que mayor demanda tienen del pueblo Ruso. Una situación similar se presenta en Brasil e Indonesia, mientras que Estados Unidos y Canadá, en el mercado internacional, tienen mayor ventaja comparativa en los productos madereros industrializados. Este fenómeno nos indica que los países que tienen mayor desarrollo económico (Estados Unidos y Canadá) tienden a importar productos madereros sin transformación. Al tiempo que exportan mayormente productos manufacturados con alto nivel de tecnología en su producción y viceversa.

\section{Conclusión}

La transformación política, social y económica de Rusia, que conllevó a la apertura comercial de este país, ha sido aprovechada positivamente, en cuanto a productos forestales se refiere. El incremento de las cantidades

Cuadro 4

Comercio total de productos madereros. Cifras acumuladas, 1992-2000 (miles de dólares)

\begin{tabular}{lrrrr}
\hline Países / años & Exportaciones & Importaciones & \multicolumn{1}{c}{ Total } & \multicolumn{1}{c}{ Saldo (X-M) } \\
\hline Brasil & $39,812,681$ & $8,186,377$ & $47,999,058$ & $31,626,304$ \\
Canadá & $397,619,796$ & $53,138,162$ & $450,757,958$ & $344,481,634$ \\
Estados Unidos & $280,025,886$ & $353,380,833$ & $633,406,719$ & $-73,354,947$ \\
Indonesia & $114,414,887$ & $10,607,353$ & $125,022,240$ & $103,807,534$ \\
Rusia & $119,279,418$ & $14,296,152$ & $133,575,570$ & $104,983,266$ \\
Total & $951,152,668$ & $439,608,877$ & $1,390,761,545$ & $511,543,791$ \\
\hline
\end{tabular}

Fuente: www.fao.org/FAOSTAT. 
comercializadas en la arena internacional es la prueba evidente (26.2 por ciento en las importaciones y 11.2 por ciento en las exportaciones, ambos promedios anuales de 1992 a 2000) de la segura inserción del país ex socialista al sistema de mercado capitalista.

El análisis comparativo de los grandes poseedores de la cubierta forestal del planeta nos hace concluir que las relativamente bajas cantidades comercializadas del país con mayor superficie forestal del planeta (Rusia), son consecuencia del retraso tecnológico de la industria forestal y de su reciente apertura comercial. Lo anterior debido al tipo de mercancía que se importa y se exporta (se vende al exterior producto con poco valor agregado y se importa lo contrario), y también porque aunque el comercio internacional de productos forestales de Rusia no es reciente, su alcance era limitado, pero tendió a ampliarse a partir de los noventa, cuando inició su apertura de mercado al exterior.

Tanto las autoridades como los productores rusos están empleando de manera acertada programas de sustentabilidad forestal, la única manera de asegurar la regeneración de los bosques. De no ser así, a mediano o largo plazo las externalidades negativas que provoca la ausencia de los recursos forestales traerían perjuicios económicos y sociales, al verse minada no sólo la salud de sus habitantes sino la del mundo.

Por último, recordando las tres variables aquí analizadas - deforestación, exportaciones e importaciones - se puede afirmar que $\mathrm{Ru}$ sia, con su propia estructura productiva, hace un buen manejo de la riqueza forestal que la naturaleza le proporcionó, ya que aun con el uso comercial que se le ha dado y con la tala ilegal en algunas regiones del país, logró incrementar su superficie boscosa en un promedio anual de 0.02 por ciento durante la década de los noventa, hecho contrario a la tendencia mundial y superado únicamente por el país más poderoso del grupo, Estados Unidos.

\section{Bibliografía}

CEPAL (1995) Medio ambiente y comercio internacional en América Latina y el Caribe, en SELA/UNCTAD, Comercioy medio ambiente. Venezuela: Editorial Nueva Sociedad. Esty, Daniel (2001) El reto de la Organización Mundial de Comercio. España: Editorial Gedisa.

FAO (2003) State of the World's Forests, FAO Forestry Department Press, Italia.

Fossart, Robert (1994) El mundo en el siglo XXI. México: Siglo Veintiuno Editores.

Glender Alberto, Lichinger Víctor (1994) La diplomacia ambiental, México y la Conferencia de las Naciones Unidas sobre el medio ambiente y Desarrollo. México: Fondo de Cultura Económica.

Gómez-Pompa Arturo, del Amo Silvia (1994) "El manejo sustentable de los bosques", en Glender Alberto, Lichinger Víctor (1994) La diplomacia ambiental, México y la Conferencia de las Naciones Unidas sobre el medio ambiente $y$ Desarrollo. México: Fondo de Cultura Económica.

Gorvachev, Mijail (1992) El golpe de agosto. México: Editorial Diana.

Horowitz, Evelyn (1995), El vínculo comercio/medio ambiente, en SELA/UNCTAD, 1995, "Comercio y Medio Ambiente", Editorial Nueva Sociedad, Venezuela.

Kaul Inge, Gruenberg Isabelle, Stern Marc (1999) Bienes públicos mundiales: la cooperación internacional en el siglo $X X I$. EU: Oxford University Press.

Leff, Enrique (2000) Saber ambiental, sustentabilidad, racionalidad, complejidad, poder. México: Siglo Veintiuno Editores, segunda edición.

Ludevid, Manuel (1998) El cambio global en el medio ambiente, editorial Alfaomega, México.

Mahar, Dennos (1989) Government Policies and Deforestation in Brazil's Amazon Region, Publicado por el World Bank Publication, Washington, D.C. USA.

McBeath Jerry (2003) Perspectives on Deforestation. EU: Massachussettss Institute of Technology, Global Environmental Politics.

Ned Lebow, Richard (1994) The Long Peace, the End of the Cold War, and the Failures of Realism. EU: International Organization.

Samuelson Paul, Nordhaus William (2002) "La protección al medio ambiente", en Samuelson Paul, Nordhaus William, Economía. Madrid: McGraw Hill, decimoséptima edición.

SELA/UNCTAD (1995) Comercio y medio ambiente. Venezuela: Editorial Nueva Sociedad.

\section{Internet}

Knight, Danielle (2000) "Rusia: inminente desastre ecológico en la isla Sajalin" editado por Rebelión, periódico electrónico de información alternativa. www.rebelio.org/ ecologia/sajalin230800.htm.

Información forestal por país, www.fao.org/forestry

Información estadística: www.fao.org/FAOSTAT 


\section{Notas}

1 Robert Fossart. El mundo en el siglo XXI. México: Siglo veintiuno editores, 1994 , pp. 243-265.

2 Mijail Gorvachev. El golpe de agosto. México: Editorial Diana, 1992, pp. 11-13.

3 Richard Ned Lebow. "The Long Peace, the End of the Cold War, and the Failures of Realism",International Organization, United States, 1994.

4 Robert Fossart, op. cit., pp. 298-299.

5 FAO. Situación de los bosques del mundo. Italia, 2001.

6 China tiene mayor superficie forestal que Indonesia, pero por la pertinencia de no sobrepasar por mucho el 50 por ciento se optó por este último.

7 Manuel Ludevid, "El cambio global en el medio ambiente" Alfaomega editorial, México 1998, Pp. 202-248

8 Samuelson Paul, Nordhaus William, "La protección al medio ambiente", en Samuelson Paul, Nordhaus William, Economía. Madrid: McGraw Hill, decimoséptima edición, 2002, p. 342.

9 Más del noventa por ciento de las especies conocidas viven en las selvas tropicales (UNEP/Earthscan, 1999).

10 Samuelson Paul, Nordhaus William, op. cit., p. 340343

11 inge Kaul, Gruenberg Isabelle, Stern Marc. Bienes públicos mundiales: la cooperación internacional en el siglo XXI. EU: Oxford University Press, 1999, p. 4.

12 FAO. "State of the World's Forests", Forestry Department Press, Italia, 2003, p. 53.

13 Enrique Leff. Saber ambiental, sustentabilidad, racionalidad, complejidad, poder. México: Siglo XXI Editores, 2000, segunda edición, pp. 18-19.
14 Alberto Glender, Lichtinger Victor (compiladores), La diplomacia ambiental, México y la Conferencia de las Naciones Unidas sobre el Medio Ambiente y Desarrollo, SER, Fondo de Cultura Económica, México, 1994, p. 7.

15 Gómez Arturo, del Amo Silvia "El manejo sustentable de los bosques", en Glender Alberto, Lichinger Victor (1994) La diplomacia ambiental, México y la Conferencia de las Naciones Unidas sobre el medio ambiente y Desarrollo. México: Fondo de Cultura Económica, 1994, pp. $153-158$

16 Las plantaciones forestales desempeñan tres funciones principales: 1) rehabilitación del medio ambiente -la conservación de suelos y aguas-, 2) producción de madera y 3) la ordenación forestal sostenible.

17 Danielle Knight. "Rusia: Inminente desastre ecológico en la isla Sajalin”, 2000, editado por Rebelión, periódico electrónico de información alternativa. p. 1 .

18 CEPAL. "Medio ambiente y comercio internacional en América Latina y el Caribe", en SELA/UNCTAD Comercio y medio ambiente. Venezuela: Editorial Nueva Sociedad, p. 65.

19 Evelyn Horowitz. "El vínculo comercio/medio ambiente", en SELA/UNCTAD, Comercio y Medio Ambiente, Venezuela: Editorial Nueva Sociedad, 1995, pp.11-12.

20 Daniel Esty. El reto de la Organización Mundial de Comercio. España: Editorial Gedisa, 2001, p. 16.

21 Horowitz, Evelyn, op. cit., p. 12.

22 Dennos J. Mahar nos dice que las causas de la deforestación en Brasil varían según la región, pero concluye que la agricultura es la principal causa. "Este tipo de actividades lleva a la depredación de 150000 km² de selva cada año" (1989: 2). т:? 